that sugar raises the plasma concentration of cholesterol in man. The report refers to the "very low carbohydrate diets" commonly used for the treatment of obesity and says that they cause an increase in plasma cholesterol. The commonly used diet is not very low in carbohydrate-it contains something like $60 \mathrm{~g}$ a day-and it certainly does not increase plasma cholesterol.

The main failing of the report is its dedication to the hypothesis that the concentration of blood cholesterol is the dominan feature of CHD. The fact is that there are many other features; among these are a raised concentration of triglyceride and uric acid and a diminished glucose tolerance. A search for the causes of CHD should seek factors that produce as many as possible of these features. Alternatively, it should seek hormonal changes that almost certainly underlie this range of abnormalities that characterise the disease how else do we explain the considerable difference in disease prevalence between men and premenopausal women? So far an acceptable candidate is insulin; it may, however, well be that the primary disturbance is in some other hormone 67

\section{JOHN YUDKIN}

London NW3

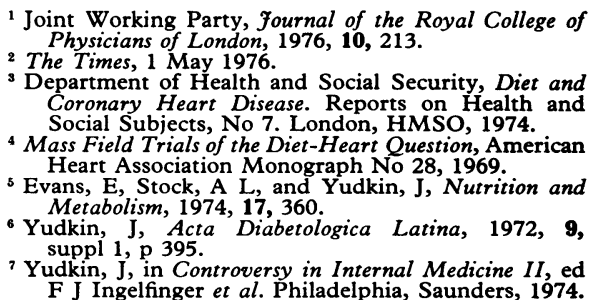

\section{Myocardial infarction}

SIR,-Dr H G Mather and others (17 April, p 925) have made inadequate conclusions from their own study. Although they quote Christiansen et $a l^{1}$ as showing that the introduction of coronary care units has been associated with a fall in the hospital mortality rate their own figures demonstrate that the mortality rates for patients treated at home do not for the most part differ significantly from those for patients treated initially in coronary care units in hospital. Not only was it confirmed that some patients, especially those who are initially hypotensive or who have a history of angina or of myocardial infarction, have a poor prognosis wherever they are treated, but also it is shown that other patients, especially those over 60 years of age, may do better if treated at home. What is certainly not demonstrated is that there is a place at all for coronary care units. The recently published joint report on coronary care by the Royal College of Physicians and the British Cardiac Society ${ }^{2}$ is more courageous in its conclusion in this respect.

It might be thought unethical to include in a controlled study a group of patients for whom the medical profession did nothing whatever in hospital or in general practice. None the less, I venture to suggest that one of the conclusions that may possibly be drawn from this paper is that the influence of the medical profession is questionable, and moreover the paper may even reinforce Illich's view that not only are coronary care units of doubtful advantage ${ }^{3}$ but in some cases there may be a direct correlation between the amount of professional medical activity and the increased morbidity of the patient. This surely is the true conclusion to be drawn from the figures that demonstrate that no group of patients does specifically better in a coronary care unit and one group may indeed do significantly worse.

The opening statement of the paper, "Because of the increase in the number of deaths from coronary heart disease, improvement in the treatment of this condition is a matter of urgent concern," is fundamentally wrong.

The report of the Joint Working Party ${ }^{2}$ summarising current knowledge and research work concluded that $40 \%$ of coronary deaths occur within the first month, the majority of those within the first hour, and the majority of those within the first few minutes. Twothirds of all fatal attacks are medically unattended. The disease now kills 35000 men and women of under retirement age every year in the UK. My belief is that there is no practical system of postcoronary care that could possibly influence these figures to any significant degree. There is no possible framework of clinical organisation that could cope with these numbers at the right time and in the right place even if the treatment was effective. Prevention, not treatment, is what should be the matter for urgent concern. To that event the authors' suggestions on the management of acute myocardial infarction are an irrelevance in the wider sphere of the management of ischaemic heart disease.

ROBERT LEFEVER

London SW7

${ }^{1}$ Christiansen, I, Iverson, K, and Skouby, A P, Acta Medica Scandinavica, 1971 , and 9804 Joint Working Party, Journal of the Royal College of Physicians of London, 1975, 10 5 . I Ivan Illich, Medical Nemesis, p 51. London, 1974.

\section{Regression of atherosclerosis}

SIR,-There has been much interest lately in the possibility of causing regression of atheromatous plaques by giving polyunsaturated fats by mouth. I should like to suggest that, of all sites in all arteries, it is the progress of atherosclerotic plaques in cerebral arteries that can be assessed most effectively because the reduction of cerebral blood flow caused thereby-and the increase of cerebral blood flow when plaques regress-can be monitored readily by the resulting effect on behaviour, which changes in certain recognisable ways that are observable and recordable.

Some 14 years ago I conducted an investigation along these lines, ${ }^{1}$ using large doses of corn oil emulsion combined with a reduction of dietary animal fats, and found indeed that behaviour in atherosclerotic dements (though not in senile dements) improved, in particular in respect of incontinence. Since then I have been using corn oil emulsion in other cases of atherosclerotic dementia, enabling many patients to leave hospital and to lead relatively normal lives in the community again.

\section{H DALE BECKETT}

\section{Cane Hill Hospital,}

Coulsdon, Surrey

1 Beckett, H D, fournal of Mental Science, 1962, 108,

\section{Sociological realities}

SIR,-It is interesting to see from your leading article (3 April, p 790) that you are a disciple of Chairman Mao. Your conversion is probably not total, for I doubt whether you want to promote the notion of the "barefoot doctor", but the barefoot social worker is obviously your ideal, and positively Mao-like is your scorn for the pedagogues who seek to keep the student social worker in the classroom rather than the rice-fields, or at any rate their urban equivalent.

All the internal evidence suggests that you know little at first hand about social work and nothing about social work education. Ignorance, however, is venial; arrogance is not. So powerful is the unexamined assumption which dominates the article, that social workers are useful pairs of hands with minimal educational needs, that the uninformed reader is bound to emerge with wholly misleading notions of the purpose and arguments of the document supposedly under review. The CCETSW paper is not faultless: in common with most global reviews of educational policy it has its pretentious moments. But its goal is a useful one and its concerns are essentially practical. Who would suppose, having read the $B M F$ account, that the main emphasis of the paper in question was precisely on the need to give priority to training for practice skills rather than to academic knowledge ?

In fact, neither the authors of the report nor you need feel unduly alarmed at the prospect of social work students waddling out of their training courses like so many Strasbourg geese, stuffed to bursting point with arcane theories. The exigencies of time-tabling alone impose a more varied and less heady diet. My own department, which is typical of many, takes young (and some not so young) graduates and completes their professional training in either one or two years, according to the type of first degree course they have followed. At least half of that time must be spent in learning practical skills, under supervision, in local authority departments, hospitals, health centres, or voluntary organisations. A student whose first degree was in Russian or zoology has therefore only the equivalent of one year in which to acquire the necessary "knowledge base" for social work practice, the social sciences graduate only half a year. Uncertainty about the essential components of the "knowledge base" does not imply, as you imagine, doubts as to what a social worker's job is but rather a continuing attempt to define those specific areas of knowledge most relevant to the job. Inevitably this means stringent selection and the elimination of a very great deal which, though of considerable interest, is not of central relevance to the professional task.

For you, of course, there are few problems. You know what a straightforward task the social worker has and how useless it is to do very much more than throw him into the world of practice. Having spent more than a decade on the staff of a medical school, I can imagine the outcry that would (quite properly) go up if I were sufficiently philistine to argue in your columns that it is an absurd waste of time to fill the heads of medical students with anatomy, physiology, biochemistry, and pharmacology instead of concentrating on practicalities. I would rapidly be reminded that a professional man is distinguished from a technician, inter alia, by the fact that he understands the theoretical principles underlying the practical measures he takes. You would no doubt deny 
the relevance of the analogy and argue that social workers, if not in managerial or teaching positions, are essentially technicians rather than professionals. I am quite certain that there are technician-type jobs to be done in social service departments but equally that many social work tasks demand high levels of professional skill and professional knowledge.

By far the greater part of the "classroom" education of social work students is carried out by people with considerable experience of social work practice. Academic sociologists, contrary to your assumption, play quite a small role. But they, together with representatives of other social science disciplines as well as of medicine, have an essential function in helping our student to understand the nature and causes of the problems they encounter in practice. Some of these problems are of a horrendous complexity, and common sense and good will, though essential, do not provide an adequate basis for wise assessment and informed decisions: we need systematic knowledge as well. Anti-intellectualism is rather in fashion at present, and it has some adherents among social workers. But it is sad to see a distinguished medical journal offering its support.

F M MARTIN

Department of Social Administration and Social Work,
University of Glasgow

\section{Caesarean section and respiratory distress syndrome}

SIR,-A number of points arise from your leading article on this subject (24 April, p 978). In quoting figures from the 1958 British Perinatal Mortality Survey you do not mention the significantly higher incidence of "hyaline membrane disease" in pre-labour than in during-labour sections and in the latter compared with vaginal deliveries. ${ }^{1}$ It has long been my impression that there is a lower incidence or a milder form of respiratory distress syndrome (RDS) associated with caesarean sections performed after rupture of the membrane compared with sections in the presence of intact membranes. Experimental work on the rabbit shows that full aeration of the lungs occurs within 10 minutes of vaginal delivery but that after caesarean section it takes six hours. ${ }^{2}$ Indeed in the lamb the lungs contain a volume of fluid that is equivalent to the functional residual capacity after breathing has been established and similarly this takes about five hours to be removed, via lymphatics and the interstitial space of the lungs. ${ }^{3}$ The high surface tensions of a surfactant deficiency state would hinder the reabsorption of this inconvenient mass of fluid, thus contributing to the respiratory difficulties. We must not dismiss the chest-squeezing seen in normal delivery and in the procedure of Reis et al, which you quote. The significance of the inability to drain liquor may be relevant in the case of twins. The incidence of RDS and of resultant deaths is higher in the second twin. ${ }^{45}$ In one series ${ }^{5}$ the incidence of RDS (from which the infant recovered) was 3.2 times greater in the second twin than in the first; similarly there were $2 \cdot 1$ times more deaths in second twins as the result of RDS. The higher overall mortality of the second twin due to anoxia cannot completely explain this difference and I suggest that it is due to the fact that drainage of liquor from the amniotic sac lessens the incidence of RDS.
If only pulmonary maturation did occur "precisely at 35 weeks of gestation"! It is true to say that the lecithin : sphingomyelin ratios of a population tend to rise at 35 weeks, but individuals do not always conform. Indeed, I have recently demonstrated that the mean regression line for female infants reaches 2.0 at $35 \frac{1}{2}$ weeks but that for males it does not do so until almost $36 \frac{1}{2}$ weeks. Thus for twins of different sexes, perhaps regardless of birth order, the boy is more likely to develop RDS than the girl at any given gestational age in the risk period up to, say, 37 completed weeks. In this borderline area of susceptibility to RDS all possible measures must be taken to prevent it.

Stratford-upon-Avon

Robert Pearson

Fedrich, J, and Butler, N R, Lancet, 1972, 2, 768 Adams, F H, et al, fournal of Pediatrics, 1971, 78, 837. Strang, L B, in Development of the Lung (C Cohen, M M, Weintraub, D H, and Lilienfeld, A M Pediatrics, $1960,26,42$.

Neligan, G, Robson, E, and Hey, E, Pediatrics, 1969,

43, 143 .
Pearson, to be published.

SIR,-Your leading article on this subject (24 April, p 978), while providing a timely reminder that delivery by caesarean section may be associated with a serious neonatal hazard, contains a dangerously misleading error-namely, the statement that "it is precisely at 35 weeks of gestation that pulmonary-maturity is attained." If this was so, then the management of almost all pregnancies in which placental dysfunction is suspected would indeed be a very simple matterdelivery would be arranged for exactly. 35 weeks.

The fact of the matter is very different in that the developmental time-table for different tissues and systems, including the lungs, varies from fetus to fetus. In this journal my former colleagues and I described how there is sometimes adequate fetal lung surfactant as early as the 32nd week of gestation, but that in other pregnancies this may not occur until almost term. ${ }^{1}$ Unless the now widely available amniotic fluid surfactant tests are used (in preference to an imaginary fixed gestational time-table) to confirm sufficient pulmonary maturation in the fetus readily avoidable neonatal deaths from respiratory distress will continue to occur and some high-risk fetuses with already "safe" lungs will be left to die in utero.

C R WHITFIELD

Department of Obstetrics and

Gynaecology,

University Hospital of South Manchester,

$$
\text { 2, } 85 \text {. }
$$

\section{Oestrogens as a cause of endometrial carcinoma}

SIR,-Your leading article (3 April, p 791) reviewed the papers of Smith et $a^{1}$ and Ziel and Finkle ${ }^{2}$ and concluded with the unwarranted recommendation that synthetic oestrogens and oestrone sulphate in its various forms should be avoided in the treatment of postmenopausal women. Ziel and Finkle did not consider the effect of the initial. selection of their 94 patients into the care of the Kaiser Permanente Medical Center in Los Angeles or reflect on the original indications for oestrogen therapy in this group of privately insured, middle-class patients. ${ }^{3}$ They did not examine the effect of parity alone or the interactions between parity, obesity, and age of menopause, nor did they examine the incidence of diabetes, hypertension, or previous anovulation. The pathological diagnoses were not examined independently; it is notoriously difficult to make an unequivocal diagnosis of endometrial adenocarcinoma in an oestrogen-treated patient. The apparent lesion may be extremely localised to the superficial stratum of the endometrium and treatment with a progestogen or curettage some six weeks after stopping the medication may result in the disappearance of the lesion. In the subsequent correspondence Ziel and Finkle ${ }^{4}$ indicated that only 15 of the 94 patients had deep myometrial invasion, suggesting that a large proportion of these patients may even have had their disease diagnosed earlier than expected because they were under continuing medical supervision. The incidence of undiagnosed endometrial malignancy can be only conjectural in the control patients who had not had the benefit of specific medical inquiries about any vaginal bleeding. Hysterectomy is unlikely to have influenced the data as the type of patient having hysterectomy is more likely to be the parous woman, not one of high risk for endometrial carcinoma; indeed, quite different hysterectomy rates in the United States and the United Kingdom do not appear to have influenced the respective incidences of the disease in the two countries.

The paper of Smith et al shows that the relative risks of endometrial carcinoma vary by disease of the comparison group (cervical, vulvar, or ovarian carcinoma) and by hospital examined as well as year of diagnosis and age of diagnosis, suggesting that "the attempt to quantify patient heterogeneity is incomplete." They indicate that "a pattern [emerges] of endometrial carcinoma developing in large numbers of persons who do not possess the previously reported constitutional physiologic features associated with the disease," yet they themselves state that the second and third National Cancer Surveys showed essentially no change in the incidence of endometrial carcinoma between the years 1947 and 1970 . These two papers cannot then be taken as authoritative assessments of the risk of oestrogen in postmenopausal patients.

The hypothesis of Siiteri and MacDonald is incompletely set forth. It states ${ }^{5}$ that "the exclusive production of estrone in the presence of the proper genetic background and other initiating agents, whether they be virus or carcinogens, appears to play an important role in the development of neoplasia of estrogen target organs" (my italics) and again "the constitutional stigmata that give rise to increased extraglandular estrone production are precisely those that appear to favor an increased occurrence of endometrial neoplasia."6 These qualifications suggest that controls matched for these constitutional characteristics are essential in any study to test the role of oestrogen in this disease and that the hypothesis relates exclusively to endogenous production of hormone.

The biochemical arguments marshalled against oestrone also need careful appraisal. It is true that oestradiol is much more tightly bound to preparations of premenopausal human endometrial nuclei than oestrone. ${ }^{78}$ However, studies using whole cells ${ }^{2}$ have shown that oestradiol and oestrone enter the endometrial cell with equal facility, that they are 